\title{
A LEI GERAL DE PROTEÇÃO DE DADOS PESSOAIS E SEUS EFEITOS EM RELAÇÃO À PROTEÇÃO ESPECIAL DESTINADA ÀS CRIANÇAS E AOS ADOLESCENTES NA INTERNET
}

\section{THE GENERAL LAW ON THE PROTECTION OF PERSONAL DATA AND ITS EFFECTS IN RELATION TO SPECIAL PROTECTION FOR CHILDREN AND TEENAGERS AT INTERNET}

\author{
Ana Carolina dos Santos Souza*
}

\begin{abstract}
Resumo
O presente artigo tem como objetivo a análise dos efeitos provenientes da Lei $\mathrm{n}^{\circ}$ 13.709, promulgada em 14 de agosto de 2018 , no que concerne à proteção especial destinada ao tratamento dos dados pessoais das crianças e dos adolescentes na sociedade da informação. A nova lei adota como diretriz para a proteção do tratamento de dados pessoais desses indivíduos o conceito de respeito ao melhor interesse, o qual deverá ser compreendido sob a ótica da Doutrina da Proteção Integral já consolidada no ordenamento jurídico brasileiro, presente em legislações como a Constituição Federal de 1988, o Código Civil de 2002, o Estatuto da Criança e do Adolescente e a Convenção sobre os Direitos da Criança. Portanto, faz-se necessária a análise, no aspecto fático, da forma como a referida lei irá produzir efeitos acerca de tal proteção especial, de acordo com o seu artigo 14, bem como as razões atinentes à sua criação.
\end{abstract}

Palavras-chave: Dados pessoais. Proteção Especial. Melhor interesse. Crianças e adolescentes. Sociedade da informação.

\begin{abstract}
The article aim to analyze the effects of law number $13.709 / 2018$, claiming special protection regarding personal data of children and teenagers in the information society. As a guideline, it adopts the concept of respect to the best interest, which should be understood by the perspective of the Doctrine of Integral Protection, already consolidated in Brazil's legal system, presente in the legislation as the Federal Constitution of 1988, 2002 Civil Code, Statue of Children and Adolescentes and Convention on the Rights of the Child. Therefore, na analysis is needed in the factual aspect about how the mentioned law will maintain its effects concerning the special protection, regarding article 14, as well the reasons related its creation.
\end{abstract}

Keywords: Personal data. Special protection. Best interest. Children and teenagers. Information society.

Artigo submetido em 15 de junho de 2020 e aprovado em 20 de agosto de 2020

\footnotetext{
* Graduanda em Direito pela Pontifícia Universidade Católica de Minas Gerais. Monitora de Teoria Geral do Direito no $2^{\circ}$ semestre de 2019 e de Direito Civil I e II no $1^{\circ}$ semestre de 2020, sob a supervisão da professora Dra. Taisa Maria Macena de Lima. E-mail: carolis.souza@ hotmail.com.
} 


\section{INTRODUÇÃO}

A Lei $n^{\circ} 13.709$ de 2018 inaugura no ordenamento jurídico brasileiro um verdadeiro sistema de proteção aos dados pessoais, na medida em que dispõe acerca dos fundamentos que servirão como base para a sua coleta, o seu compartilhamento e o seu tratamento, os quais são tidos pelos especialistas em Direito e Informática como o petróleo do século XXI ${ }^{1}$.

É inegável que se trata de uma temática de grande relevância no atual cenário jurídico não apenas brasileiro, como também mundial, tendo em vista o fato de a sociedade contemporânea encontrar-se inserida em um contexto tecnológico no qual as relações interpessoais vêm se (re)construindo através da utilização de aparelhos digitais e das redes sociais, de maneira que o indivíduo tem, na palma de suas mãos, com poucos cliques, acesso a infinitas possibilidades de interações, por meio das quais suas informações pessoais são captadas.

Imperioso ressaltar que existe, dentre os usuários das plataformas digitais, uma grande parcela de indivíduos considerados incapazes sob a ótica do Código Civil de 2002 - tanto absolutamente, como os menores de 16 (dezesseis) anos, quanto relativamente, abrangendo aqueles que têm entre 16 (dezesseis) e 18 (dezoito) anos, que nasceram imersos em tal sociedade tecnológica, se encontrando familiarizados com a rede, os aparelhos e sempre estão conectados.

Dessa forma, uma vez que as crianças e os adolescentes utilizam a tecnologia de modo quase inerente à sua maneira de interação com o mundo, é uma decorrência lógica o fato de os seus dados pessoais serem coletados pelas plataformas e mídias digitais com as quais interajam. Tendo em vista esse contexto, a Lei Geral de Proteção de Dados Pessoais, Lei ${ }^{\circ}$ 13.708 de 2018, dedicou a Seção III do seu Capítulo II ao tratamento de dados pessoais de crianças e adolescentes, na qual estabeleceu no artigo 14 , caput e $\S 1^{\circ}$, que:

Art. 14. O tratamento de dados pessoais de crianças e de adolescentes deverá ser realizado em seu melhor interesse, nos termos deste artigo e da legislação pertinente. $\S 1^{\circ}$. O tratamento de dados pessoais de crianças deverá ser realizado com o consentimento específico e em destaque dado por pelo menos um dos pais ou pelo responsável legal. (BRASIL, 2018)

\footnotetext{
1 ““‘Os dados pessoais são tidos como o novo petróleo, têm um valor ainda maior, e as pessoas ainda não têm ideia de quanto valem suas informações sociais nessas transações eletrônicas", afirmou Eduardo Magrani, participante do encontro Legalite PUC-Rio: Internet das Coisas - Regulação e Privacidade, organizado pelo núcleo de pesquisa e ensino Legalite, dos departamentos de Informática e Direito da PUC-Rio.” Disponível em: http://jornaldapuc.vrc.puc-rio.br/cgi/cgilua.exe/sys/start.htm?infoid=5247\&sid=53. Acesso em: 26 abr. 2020.
} 
A redação da supracitada norma denota a preocupação do legislador em tutelar os dados pessoais das crianças e dos adolescentes inseridos no ambiente virtual, trazendo à tona a necessidade de respeitar o melhor interesse desses indivíduos quando do tratamento de seus dados pessoais, que dependerá, para as crianças, especificamente, do consentimento específico de seus pais ou responsáveis legais.

Sendo assim, é necessário analisar os motivos pelos quais a legislação em apreço adotou o conceito de melhor interesse ao tratamento de dados pessoais de tais indivíduos, bem como condicionou a sua realização ao consentimento dos pais e dos responsáveis, em especial, das crianças, levando em conta as disposições existentes no ordenamento jurídico brasileiro acerca da proteção integral conferida à estes indivíduos, quais sejam, a Constituição Federal de 1988, o Estatuto da Criança e do Adolescente, o Código Civil de 2002 e a Convenção sobre os Direitos da Criança, tendo em vista o fato de serem sujeitos em desenvolvimento, incapazes - absoluta ou relativamente -, que necessitam de representação para praticar os atos da vida civil.

Para tanto, mister contextualizar o cenário histórico-social do mundo contemporâneo que impulsionou a promulgação da supracitada legislação no Brasil, bem como o sistema por ela inserido ao ordenamento jurídico pátrio, para, então, discorrer acerca da latente necessidade de destinar uma proteção especial aos dados pessoais das crianças e dos adolescentes usuários das tecnologias e das mídias sociais.

\section{O CONTEXTO QUE PROPICIOU A CRIAÇÃO DA LEI GERAL DE PROTEÇÃo DE DADOS PESSOAIS NO BRASIL}

A atividade humana da sociedade contemporânea vem sendo moldada através da utilização de aparelhos digitais e das redes sociais, de modo que se pode falar na existência de uma necessidade, e, até mesmo, de um certo desejo implícito por parte dos indivíduos de estarem conectados, obtendo informações e interagindo, em tempo real, com todo o planeta, por meio de dispositivos que cabem na palma de suas mãos.

Para o sociólogo Manuel Castells, a sociedade da informação pode ser entendida como "um período histórico caracterizado por uma revolução tecnológica, movida pelas tecnologias digitais de informação e comunicação" (CASTELLS, 2002. p. 108). Nesse sentido, entende o autor que como a informação é inerente às práticas do ser humano do século XXI, sua 
existência, inclusive em relação ao mundo que o cerca, é moldada de acordo com a tecnologia.

E é nesse contexto que os indivíduos vão deixando, clique após clique, um pouco de si, de sua personalidade e privacidade, nas redes. No processo de adquirir um aparelho e conectar-se ao mundo digital, o usuário deve fornecer - pois se trata dos chamados "campos obrigatórios" para cadastro -, desde sua localização no globo, passando por sua idade, endereço eletrônico, como também seu gênero, orientação sexual, dentre outros. Desse modo, é fato que a tecnologia vem tratando os dados pessoais dos indivíduos como a matéria prima de uma verdadeira revolução na forma de se comportar e de consumir no cenário da sociedade da informação.

Diante da inegável importância que vem sendo atribuída aos dados pessoais nas últimas décadas, o Parlamento de Hessian, na Alemanha, nos anos 1970, aprovou uma prospecção legislativa acerca do tema, a qual foi considerada o ponto de partida para a edição, tempos depois, da Diretiva 95/46/CE, texto legal que entrou em vigor no ano de 1995 no cenário do Direito europeu, por meio do qual disciplinou de forma ampla a proteção de tais informações, através de princípios e direitos básicos, funcionando como uma espécie de instrução aos países membros da União Europeia sobre a maneira de elaborar suas normas internas atinentes à questão ora em apreço.

Desse olhar atento por parte do supramencionado bloco europeu acerca da proteção de dados, bem como pela efervescência tecnológica que, ano após ano, passou a dominar a sociedade pós moderna, emergiu a necessidade da criação de uma legislação que pudesse "harmonizar as leis de privacidade de dados em todos os Estados membros da União Europeia" (TEIXEIRA; ARMELIN, 2019, p. 21), surgindo, então, o GDPR - General Data Protection Regulation, ou Regulamento Geral de Proteção de Dados, promulgado em 2016 e em vigor desde o ano de 2018, o qual revogou a Diretiva 95/46/CE, e, além de unificar a legislação europeia acerca da matéria, trouxe à tona questões fundamentais no que tange a proteção dos dados pessoais dos indivíduos e, consequentemente, sua privacidade, no âmbito tecnológico da sociedade contemporânea.

Não obstante a vultuosa regulamentação dispensada à tais informações pelo GDPR, mister ressaltar que sua disciplina jurídica também está presente em outros países do globo, notoriamente, os Estados Unidos da América, que apesar de não possuírem um sistema unificado como o GDPR, tratam, a muito, desde os anos 1974, acerca da proteção dos dados pessoais, por meio do Privacy Act, ou Lei da Privacidade, lei federal que estabelece um 
“código de práticas justas por meio da qual haverá a coleta, a manutenção, o uso e a disseminação de informações sobre indivíduos, que são mantidas em sistemas de registros por agências federais"2.

Nesse contexto histórico-social do mundo globalizado no qual está inserido, surgiu no Brasil a premente necessidade de uma norma que tutelasse de forma unificada a privacidade dos indivíduos que consomem, cada vez mais, todo o aparato digital proporcionado pela tecnologia e fomentado pelas mídias sociais.

Antes da LGPD, existia no país uma legislação esparsa acerca do tema, como o artigo $5^{\circ}$, inciso X, da Constituição da República de 1988, que disciplina a intimidade e a vida privada; o Capítulo II do Código Civil de 2002, que regula os direitos da personalidade, sendo possível estender a proteção prevista em seu artigo $12^{3}$ aos dados pessoais; o artigo $4^{\circ}$, inciso IV da Lei de Acesso à Informação, Lei no 12.527 de 2011, que trata do conceito de informação pessoal; bem como o Capítulo II do Marco Civil da Internet, Lei $\mathrm{n}^{\circ} 12.965$ de 2014, que dispõe a respeito dos direitos e garantias dos usuários na rede, notoriamente, seu artigo $7^{\circ}$, incisos VII a $\mathrm{X}$, em que há uma disciplina especial para a coleta, o uso, o armazenamento, o tratamento e a proteção dos dados pessoais dos usuários da internet, dentre outras.

Entretanto, não havia no Brasil um sistema normativo que pudesse tutelar de forma plena tais informações, inclusive acerca das crianças e dos adolescentes, sujeitos em condição de desenvolvimento, que necessitam de maior proteção, o que foi superado com a aprovação da Lei $\mathrm{n}^{\mathrm{o}} 13.709$ de 2018 pelo Congresso Nacional, a qual contou como fator propulsor tanto o GDPR, quanto a Lei da Privacidade americana.

\section{O SISTEMA DE PROTEÇÃO DESTINADO AOS DADOS PESSOAIS NO BRASIL}

A LGPD construiu um verdadeiro sistema de proteção aos dados pessoais no Brasil, tendo unificado as normas atinentes à matéria, que, até então, se encontravam esparsas pelo ordenamento jurídico, inseridas na $\mathrm{CF} / 88$, no $\mathrm{CC} / 02$, na Lei de Acesso à Informação, no Marco Civil da Internet, dentre outras legislações, como também foi de encontro aos regulamentos de proteção de dados pessoais previstos em nações exteriores, com as quais o país cultiva relações internacionais.

\footnotetext{
${ }^{2}$ Disponível em: https://www.justice.gov/opcl/privacy-act-1974. Acesso em: 03 mai. 2020.

${ }^{3}$ Art. 12 do CC/02: Pode-se exigir que cesse a ameaça, ou a lesão, a direito da personalidade, e reclamar perdas e danos, sem prejuízo de outras sanções previstas em lei.
} 
Assim, o presente estudo se propõe a discorrer sobre os objetivos que norteiam esse sistema, os fundamentos nos quais se amolda, o âmbito de sua aplicabilidade, bem como os conceitos que lhe são próprios, a principiologia que o rege e a forma como será aplicada a responsabilização pelos danos patrimoniais, morais, individuais ou coletivos sofridos sob a sua égide, o que ver-se-á nos tópicos infra.

\subsection{Objetivos, Fundamentos e Aplicabilidade}

Propõe-se a Lei $\mathrm{n}^{\mathrm{o}} 13.709$ de 2018 , em seu artigo $1^{\mathrm{o}}$, a tratar acerca dos dados pessoais, inclusive nos meios digitais, por pessoa natural ou por pessoa jurídica de direito público ou privado, objetivando a proteção aos direitos fundamentais de liberdade e privacidade, bem como ao livre desenvolvimento da personalidade da pessoa natural. Nesse sentido, imperioso ressaltar que a sua tutela se destina aos:

[...] dados pessoais, ou seja, não são quaisquer dados que possam ser captados, mas tão somente aqueles inerentes à pessoa, tais como nome, endereço, e-mail, sexo, profissão ou aqueles que possam levar à identificação da pessoa, tais como IP (Internet Protocol; em português, Protocolo de Internet), dados estatísticos e quaisquer outros dados que, de alguma forma, levem à identificação de um único indivíduo. (TEIXEIRA; ARMELIN, 2019, p. 27)

Nesse sentido, sua disciplina se norteia, conforme exposto em seu artigo $2^{\circ}$, no respeito à privacidade; na autodeterminação informativa; na liberdade de expressão, de informação, de comunicação e de opinião; na inviolabilidade da intimidade, da honra e da imagem; no desenvolvimento econômico e tecnológico e na inovação; na livre iniciativa, na livre concorrência e na defesa do consumidor; e nos direitos humanos, no livre desenvolvimento da personalidade, na dignidade e no exercício da cidadania pelas pessoas naturais, fundamentos estes que vão de encontro aos preceitos emanados pela $\mathrm{CF} / 88$.

A Lei $n^{\circ} 13.709$ de 2018 também se preocupou em traçar, no seu artigo $3^{\circ}$, os limites dentre os quais poderá ser aplicada:

Art. $3^{\circ}$. Esta lei aplica-se a qualquer operação de tratamento realizada por pessoa natural ou por pessoa jurídica de direito público ou privado, independentemente do meio, do país de sua sede ou do país onde estejam localizados os dados, desde que: I - a operação de tratamento seja realizada no território nacional;

II - a atividade de tratamento tenha por objetivo a oferta ou o fornecimento de bens ou serviços ou o tratamento de dados de indivíduos localizados no território nacional; ou

III - os dados pessoais objeto do tratamento tenham sido coletados no território nacional. 
$\S 1^{\circ}$. Consideram-se coletados no território nacional os dados pessoais cujo titular nele se encontre no momento da coleta. (BRASIL, 2018)

Assim, é possível depreender que sua aplicabilidade abarca tanto o tratamento de dados pessoais efetuado por pessoas jurídicas de direito público, como a União, os Estadosmembro, os Municípios, as autarquias, dentre outros, e por empresas, pessoas jurídicas de direito privado, quanto por pessoas físicas, inclusive os profissionais liberais, com as condições estabelecidas em seus incisos e parágrafo $1^{\circ}$ retro mencionados.

Excetuam-se da égide de proteção da LGPD, conforme redação de seu artigo $4^{\circ}$, os dados pessoais realizados por pessoa natural para fins exclusivamente particulares e não econômicos (inciso I); aqueles realizados para fins exclusivamente jornalísticos e artísticos (inciso II, alínea 'a') ou acadêmicos (inciso II, alínea 'b'); bem como os realizados com destinação exclusiva de segurança pública (inciso III, alínea 'a'), defesa nacional (inciso III, alínea 'b'), segurança do Estado (inciso III, alínea 'c') ou atividades de investigação e repressão de infrações penais (inciso III, alínea 'd'); ou, ainda, os dados pessoais provenientes de fora do território nacional e que não sejam objeto de comunicação, uso compartilhado de dados com agentes de tratamento brasileiros ou objeto de transferência internacional de dados com outro país que não o de proveniência, neste caso, o país de proveniência deve proporcionar grau de proteção de dados pessoais adequado ao previsto pela supramencionada lei (inciso IV).

\subsection{Conceitos, Principiologia e Responsabilização}

O sistema de proteção aos dados pessoais proporcionado pela Lei no 13.709 de 2018 inseriu no ordenamento jurídico brasileiro conceitos que "são de extrema importância para a delimitação da aplicabilidade da norma jurídica em apreço" (TEIXEIRA; ARMELIN, 2019, p. 41), os quais se encontram presentes em seu artigo $5^{\circ}$ :

Art. $5^{\circ}$. Para os fins desta Lei, considera-se:

I - dado pessoal: informação relacionada a pessoa natural identificada ou identificável;

II - dado pessoal sensível: dado pessoal sobre origem racial ou étnica, convicção religiosa, opinião política, filiação a sindicato ou a organização de caráter religioso, filosófico ou político, dado referente à saúde ou à vida sexual, dado genético ou biométrico, quando vinculado a uma pessoa natural;

III - dado anonimizado: dado relativo a titular que não possa ser identificado, considerando a utilização de meios técnicos razoáveis e disponíveis na ocasião de seu tratamento; 
IV - banco de dados: conjunto estruturado de dados pessoais, estabelecido em um ou em vários locais, em suporte eletrônico ou físico;

V - titular: pessoa natural a quem se referem os dados pessoais que são objeto de tratamento;

VI - controlador: pessoa natural ou jurídica, de direito público ou privado, a quem competem as decisões referentes ao tratamento de dados pessoais;

VII - operador: pessoa natural ou jurídica, de direito público ou privado, que realiza o tratamento de dados pessoais em nome do controlador;

VIII - encarregado: pessoa indicada pelo controlador e operador para atuar como canal de comunicação entre o controlador, os titulares dos dados e a Autoridade Nacional de Proteção de Dados (ANPD);

IX - agentes de tratamento: o controlador e o operador;

$\mathrm{X}$ - tratamento: toda operação realizada com dados pessoais, como as que se referem a coleta, produção, recepção, classificação, utilização, acesso, reprodução, transmissão, distribuição, processamento, arquivamento, armazenamento, eliminação, avaliação ou controle da informação, modificação, comunicação, transferência, difusão ou extração;

XI - anonimização: utilização de meios técnicos razoáveis e disponíveis no momento do tratamento, por meio dos quais um dado perde a possibilidade de associação, direta ou indireta, a um indivíduo;

XII - consentimento: manifestação livre, informada e inequívoca pela qual o titular concorda com o tratamento de seus dados pessoais para uma finalidade determinada; XIII - bloqueio: suspensão temporária de qualquer operação de tratamento, mediante guarda do dado pessoal ou do banco de dados;

XIV - eliminação: exclusão de dado ou de conjunto de dados armazenados em banco de dados, independentemente do procedimento empregado;

$\mathrm{XV}$ - transferência internacional de dados: transferência de dados pessoais para país estrangeiro ou organismo internacional do qual o país seja membro;

XVI - uso compartilhado de dados: comunicação, difusão, transferência internacional, interconexão de dados pessoais ou tratamento compartilhado de bancos de dados pessoais por órgãos e entidades públicos no cumprimento de suas competências legais, ou entre esses e entes privados, reciprocamente, com autorização específica, para uma ou mais modalidades de tratamento permitidas por esses entes públicos, ou entre entes privados;

XVII - relatório de impacto à proteção de dados pessoais: documentação do controlador que contém a descrição dos processos de tratamento de dados pessoais que podem gerar riscos às liberdades civis e aos direitos fundamentais, bem como medidas, salvaguardas e mecanismos de mitigação de risco;

XVIII - órgão de pesquisa: órgão ou entidade da administração pública direta ou indireta ou pessoa jurídica de direito privado sem fins lucrativos legalmente constituída sob as leis brasileiras, com sede e foro no País, que inclua em sua missão institucional ou em seu objetivo social ou estatutário a pesquisa básica ou aplicada de caráter histórico, científico, tecnológico ou estatístico; e

XIX - autoridade nacional: órgão da administração pública responsável por zelar, implementar e fiscalizar o cumprimento desta Lei em todo o território nacional. (BRASIL, 2018)

Dessa maneira, ao trazer em seu bojo normativo uma terminologia específica, a LGPD "[...] cuidou de qualificar todos os sujeitos jurídicos envolvidos no tratamento de dados: titular, controlador, operador; encarregado; agentes de tratamento; órgão de pesquisa e autoridade nacional" (LIMA; SÁ, 2020, p. 32).

Não apenas, dispõe o artigo $6^{\circ}$ da supramencionada legislação especial acerca dos princípios atinentes às atividades de tratamento de dados pessoais, em especial o da boa-fé, 
Artigo: A Lei Geral de Proteção de Dados Pessoais e seus Efeitos em Relação à Proteção Especial Destinada às Crianças e aos Adolescentes na Internet

que, para o doutrinador civilista Carlos Roberto Gonçalves, "guarda relação com o princípio de direito segundo o qual ninguém pode beneficiar-se da própria torpeza" (GONÇALVES, 2018, p. 53) e pode se dividir na boa-fé subjetiva, pautada na intenção do sujeito em certa relação jurídica, e na boa-fé objetiva, disciplinada pelo ordenamento pátrio e entendida pela doutrina e pela jurisprudência como o padrão ético de observância indispensável nas condutas dos agentes.

Nessa linha de raciocínio, tem-se, no âmbito da Lei nº 13.709 de 2018, uma vasta principiologia, composta por dez princípios que compõem o sistema de proteção destinado aos dados pessoais no Brasil, quais sejam, o princípio da finalidade, traduzido na realização do tratamento para propósitos legítimos, específicos, explícitos e informados ao titular, sem a possibilidade de tratamento posterior de forma incompatível com essas finalidades (inciso I); o princípio da adequação, pelo qual deve existir uma compatibilidade do tratamento com as finalidades informadas ao titular, conforme o seu contexto (inciso II); o princípio da necessidade, que propõe uma limitação do tratamento ao mínimo necessário para a realização de suas finalidades, com abrangência dos dados pertinentes, proporcionais e não excessivos em relação às finalidades do tratamento de dados (inciso III); o princípio do livre acesso, que garante aos titulares consulta facilitada e gratuita sobre a forma e a duração do tratamento, bem como sobre a integralidade de seus dados pessoais (inciso IV); o princípio da qualidade dos dados, pelo qual aos titulares é garantida a exatidão, a clareza, a relevância e a atualização dos dados, conforme a necessidade e para o cumprimento da finalidade de seu tratamento (inciso $\mathrm{V}$ ).

Não apenas, o princípio da transparência, que garante aos titulares informações claras, precisas e facilmente acessíveis sobre a realização do tratamento e os respectivos agentes de tratamento, de acordo com os segredos comercial e industrial (inciso VI); o princípio da segurança, através do qual serão utilizadas medidas técnicas e administrativas aptas a proteger os dados pessoais de acessos não autorizados e de situações acidentais ou ilícitas de destruição, perda, alteração, comunicação ou difusão (inciso VII); o princípio da prevenção, consistente na adoção de medidas para prevenir a ocorrência de danos em virtude do tratamento de dados pessoais (inciso VIII); o princípio da não discriminação, segundo o qual não será realizado o tratamento para fins discriminatórios ilícitos ou abusivos (inciso IX); o princípio da responsabilização e prestação de contas, sendo o agente incumbido de demonstrar 
que adotou medidas eficazes e capazes de comprovar a observância e o cumprimento das normas de proteção de dados pessoais e, inclusive, da eficácia dessas medidas (inciso X).

Sendo assim, é possível depreender que a supramencionada legislação unificou a principiologia já vigente no ordenamento jurídico brasileiro acerca da matéria, disposta em normas esparsas, quais sejam, a CF/88, o CC/02, o Marco Civil da Internet, dentre outras.

Inobstante a falta de inovação neste pilar do sistema proteção aos dados pessoais, imperioso ressaltar que, diante das transformações proporcionadas pela sociedade da informação:

O trâmite legislativo, por mais célere que possa vir a ser, não consegue acompanhar os desdobramentos de uma determinada matéria, principalmente quando a mesma envolve tecnologia, como a de proteção de dados, tornando uma lei, desde a sua promulgação, incapaz de prever todos os potenciais conflitos e anseios de uma sociedade [...] faz-se indispensável a aplicação de princípios, que norteiem a aplicação da lei, pois os mesmos serão capazes de atingir eventos futuros, como novas tecnologias e distintas realidades. (TEIXEIRA; ARMELIN, 2019, p. 46)

Nesse sentido, os princípios trazidos pela Lei $\mathrm{n}^{\circ} 13.709$ de 2018 podem ser considerados um dos pilares do sistema de proteção aos dados pessoais no Brasil, se mostrando extremamente salutar, haja vista o contexto da sociedade da informação e a importância das tecnologias e das mídias sociais nas relações interpessoais do século XXI.

Ainda, disciplina a LGPD, na Seção III, que trata da Responsabilidade e do Ressarcimento de Danos, inserido no Capítulo IV, acerca dos Agentes de Tratamento de Dados Pessoais, sobre a reparação dos danos patrimoniais, morais, individuais ou coletivos causados pelos particulares em razão do exercício da atividade de tratamento de dados pessoais, em seu artigo 42.

Nesse contexto, a supramencionada legislação atribui a responsabilidade ao controlador ou ao operador. Este responderá nas hipóteses de descumprimento da lei em comento ou das orientações do controlador. Imperioso ressaltar que, nos termos do $\S 3^{\circ}$ de seu artigo 42, na hipótese de haver de um controlador, todos irão responder solidariamente, tendo sido garantido o direito de regresso contra os demais responsáveis àquele que reparar o dano ao titular, na medida de sua participação no evento danoso.

A Lei $\mathrm{n}^{\circ} 13.709$ de 2018 também trouxe a possibilidade de o juiz, no processo civil, inverter o ônus da prova em favor do titular de dados, quando for verossímil a alegação, houver hipossuficiência para fins de produção de prova ou quando a produção e prova pelo titular lhe for excessivamente onerosa, conforme aduz o $\$ 2^{\circ}$ do seu artigo 42. 
Sendo assim, é possível depreender que se trata de uma responsabilidade objetiva, o que torna desnecessária a necessidade de comprovar a culpa dos agentes de tratamento. Entretanto, poderá ser afastada por meio das chamadas excludentes de ilicitude, dispostas no artigo 43 da supracitada legislação, caso provem que não realizaram o tratamento de dados pessoais que lhes é atribuído (inciso I); que, embora tenham realizado o tratamento que lhes é atribuído, não houve violação à legislação de proteção de dados (inciso II); ou que o dano é decorrente de culpa exclusiva do titular dos dados ou de terceiro (inciso III).

\section{O TRATAMENTO DE DADOS PESSOAIS E O TRATAMENTO DE DADOS PESSOAIS SENSÍVEIS COMO ALICERCES DO SISTEMA DE PROTEÇÃO AOS DADOS PESSOAIS NO BRASIL}

Como alicerces do sistema de proteção aos dados pessoais no Brasil, a Lei no 13.709 de 2018 trouxe em seu bojo normativo orientações para o tratamento de dados pessoais, bem como para o tratamento de dados pessoais sensíveis, considerando as diferenças que os permeiam. Nesse diapasão, por tratamento de dados, conforme redação de seu artigo $5^{\circ}$, inciso $\mathrm{X}$, se tem:

Art. $5^{\circ}$. [...] X - [...] toda operação realizada com dados pessoais, como as que se referem a coleta, produção, recepção, classificação, utilização, acesso, reprodução, transmissão, distribuição, processamento, arquivamento, armazenamento, eliminação, avaliação ou controle da informação, modificação, comunicação, transferência, difusão ou extração. (BRASIL, 2018)

Desta feita, tendo em vista o conceito de dados pessoais, extraído da redação de seu artigo $5^{\circ}$, inciso I, qual seja, "informações relacionadas a pessoa natural identificada ou identificável” (BRASIL, 2018), é possível analisar os requisitos trazidos pela supramencionada legislação para o seu tratamento.

O artigo $7^{\circ}$, presente na Seção I, que trata dos Requisitos para o Tratamento de Dados Pessoais, inserido no Capítulo II, acerca do Tratamento de Dados Pessoais, dispõe sobre as hipóteses nas quais o tratamento de dados pessoais poderá ser realizado, quais sejam, mediante o fornecimento de consentimento pelo titular (inciso I); para o cumprimento de obrigação legal ou regulatória pelo controlador (inciso II); pela administração pública, para o tratamento e uso compartilhado de dados necessários à execução de políticas públicas previstas em leis e regulamentos ou respaldadas em contratos, convênios ou instrumentos congêneres (inciso III); para a realização de estudos por órgãos de pesquisa, garantida, sempre 
que possível, a anonimização dos dados pessoais (inciso IV); quando necessário para a execução de contrato ou de procedimentos preliminares relacionados a contrato do qual seja parte o titular, a pedido do titular dos dados (inciso V); para o exercício regular de direitos em processo judicial, administrativo ou arbitral (inciso VI); para a proteção da vida ou da incolumidade física do titular ou de terceiro (inciso VII); para a tutela da saúde, exclusivamente, em procedimento realizado por profissionais da saúde, serviços de saúde ou autoridade sanitária (inciso VIII); quando necessário para atender aos interesses legítimos do controlador ou de terceiro, exceto no caso de prevalecerem direitos e liberdades fundamentais do titular que exijam a proteção dos dados pessoais (inciso IX); ou para a proteção do crédito (inciso X).

Nesse contexto, primordial a questão do consentimento do titular para a realização do tratamento dos dados pessoais, que está expressa, dentre as dez hipóteses previstas no supramencionado artigo, apenas em seu inciso I. O consentimento do titular:

[...] deve ser expresso, preferencialmente por escrito; destacado, o que significa dizer que deverá existir uma cláusula destacada das demais cláusulas contratuais que contenha a expressão da vontade manifestada; livre de vícios, quais sejam, erro, dolo, coação, lesão e estado de perigo; específico, sendo vedadas autorizações genéricas para tratamento de dados pessoais sob pena de nulidade; revogável a qualquer momento, mediante manifestação expressa do titular. (LIMA; SÁ, 2020, p. 36)

Neste ponto, deve-se atentar para o princípio da transparência, previsto no artigo $6^{\circ}$, inciso VI da Lei Geral de Proteção de Dados, segundo o qual deve ser garantido aos titulares informações claras, precisas e facilmente acessíveis sobre a realização do tratamento, pois, caso contrário, o consentimento será considerado nulo.

O artigo $8^{\circ}$ da Lei $n^{\circ} 13.709$ de 2019, que trata sobre a questão da manifestação de vontade do titular para o consentimento do tratamento de seus dados pessoais, difere do que prevê o artigo $7^{\circ}$, inciso VII do Marco Civil da Internet, o qual aduz que o fornecimento dos dados pessoais dos usuários só poderia ser feito mediante consentimento livre, expresso e informado, uma vez que:

[...] prevê um consentimento livre, inequívoco e informado. As duas palavras se diferem na medida em que não basta o titular de dados externar o seu consentimento, faz-se necessário que esse consentimento seja inequívoco, que não paire dúvidas de que o titular consentiu a utilização de seus dados pessoais para aquele fim. (TEIXEIRA; ARMELIN, 2019, p. 46) 
Artigo: A Lei Geral de Proteção de Dados Pessoais e seus Efeitos em Relação à Proteção Especial Destinada às Crianças e aos Adolescentes na Internet

Ainda, de acordo com o princípio do livre acesso, disciplinado pelo artigo $6^{\circ}$, inciso IV, o titular faz jus ao direito de acesso facilitado às informações sobre o tratamento de seus dados, conforme exposto em seu artigo $9^{\circ}$ da Lei Geral de Proteção de Dados, as quais deverão ser disponibilizadas de forma clara, adequada e ostensiva acerca da finalidade específica do tratamento (inciso I); da forma e duração do tratamento [...] (inciso II); da identificação do controlador (inciso III); das informações de contato do controlador (inciso IV); das informações acerca do uso compartilhado de dados pelo controlador e a finalidade (inciso V); das responsabilidades dos agentes que realizarão o tratamento (inciso VI); e dos direitos do titular [...] (inciso VII).

Nos termos do artigo $5^{\circ}$, inciso II da Lei $\mathrm{n}^{\circ} 13.709$ de 2019, dado pessoal sensível é aquele dado pessoal sobre origem racional ou étnica, convicção religiosa, opinião política, filiação a sindicato ou a organização de caráter religioso, filosófico ou político, [...] referente à saúde ou à vida sexual, [...] genético ou biométrico, quando vinculado a uma pessoa natural. Desta feita, as disposições acerca do seu tratamento se encontram na Seção II do Capítulo II da supramencionada lei.

O artigo 11 da LGPD traz um rol taxativo das hipóteses nas quais poderá ocorrer o tratamento de dados pessoais sensíveis, quais sejam, quando o titular ou seu responsável legal consentir, de forma específica e destacada, para finalidades específicas (inciso I), ou sem fornecimento de consentimento do titular (inciso II) ${ }^{4}$, “em que a sua utilização, mesmo sem o consentimento, se justifica pelo bem do próprio titular ou da coletividade, desde que a utilização dos dados pessoais sensíveis seja indispensável [...]" TEIXEIRA; ARMELIN (2019, p. 66).

É fácil verificar que dado pessoal é um conceito mais amplo, uma vez que abrange todo tipo de informação sobre a pessoa natural: dos dados bancários aos dados genéticos. Ao receber o adjetivo sensível, o sentido da expressão se altera, passando a designar as situações existenciais descritas na norma. (LIMA; SÁ, 2020, p. 37)

\footnotetext{
${ }^{4}$ Art. 11. O tratamento de dados pessoais sensíveis somente poderá ocorrer nas seguintes hipóteses: [...] II - sem fornecimento de consentimento do titular, nas hipóteses em que for indispensável para: a) cumprimento de obrigação legal ou regulatória pelo controlador; b) tratamento compartilhado de dados necessários à execução, pela administração pública, de políticas públicas previstas em leis ou regulamentos; c) realização de estudos por órgão de pesquisa, garantida, sempre que possível, a anonimização dos dados pessoais sensíveis; d) exercício regular de direitos, inclusive em contrato e em processo judicial, administrativo e arbitral [...]; e) proteção da vida ou da incolumidade física do titular ou de terceiro; f) tutela da saúde, exclusivamente, em procedimento realizado por profissionais de saúde, serviços de saúde ou autoridade sanitária; ou g) garantia da prevenção à fraude e à segurança do titular, nos processos de identificação e autenticação de cadastro em sistemas eletrônicos, [...] exceto no caso de prevalecerem direitos e liberdades fundamentais do titular que exijam a proteção dos dados pessoais.
} 
Nesse sentido, trata-se de uma “[...] reação a situações de estigmatização, exclusão ou segregação, que, não raro, se verificam com o mau uso de informações sobre saúde, sexualidade, religião, etnia etc" (LIMA; SÁ, 2020, p. 37), que compõe um dos alicerces no sistema de proteção aos dados pessoais construído no Brasil pela LGPD.

Através da redação do parágrafo $1^{\circ}$ do supracitado artigo 11 , tem-se que qualquer tratamento de dados pessoais que revele dados pessoais sensíveis e que possa causar dano ao titular será regido sob a égide do disposto em seu caput e incisos, sendo uma premissa que haja, para tanto, o consentimento do responsável legal.

Dessa feita, mister salientar que as hipóteses nas quais não se exige a anuência do titular dizem respeito, em regra, à “concretização de interesse público (proteção da vida ou incolumidade pública ou tutela da saúde, por exemplo), que o legislador deu prevalência sobre interesse do titular dos dados" LIMA; SÁ (2020, p. 39).

\section{A PROTEÇÃO ESPECIAL DESTINADA AO TRATAMENTO DOS DADOS PESSOAIS DAS CRIANÇAS E DOS ADOLESCENTES}

A Lei $n^{\circ} 13.709$ de 2018, ao construir o sistema de proteção aos dados pessoais no Brasil, não se preocupou apenas em delimitar objetivos, traçar conceitos e definir o âmbito de sua aplicabilidade. Pelo contrário, a supramencionada legislação tem como um de seus alicerces a regulamentação do tratamento de dados pessoais de crianças e adolescentes, o que denota o entendimento pelo legislador pátrio de que esses indivíduos são sujeitos em desenvolvimento e exigem uma proteção especial.

Dessa maneira, a LGPD vai de encontro à Convenção sobre os Direitos da Criança, à $\mathrm{CF} / 88$, ao $\mathrm{CC} / 02$, ao $\mathrm{ECA}$, bem como às legislações europeia e estadunidense atinentes ao tema.

Nesse sentido, aduz Tânia da Silva Pereira:

O Brasil incorporou, em caráter definitivo, o princípio do "melhor interesse da criança" em seu sistema jurídico, e sobretudo, tem representado um norteador importante para a modificação das legislações internas no que concerne à proteção da infância em nosso continente. (PEREIRA, 2000, p. 31-49)

Assim sendo, preconiza a CF/88, em seu artigo 227, ser "dever da família, da sociedade e do Estado assegurar à criança, ao adolescente e ao jovem, com absoluta prioridade, o direito à [...] dignidade, ao respeito, à liberdade [...]” (BRASIL, 1998). Na 
Artigo: A Lei Geral de Proteção de Dados Pessoais e seus Efeitos em Relação à Proteção Especial Destinada às Crianças e aos Adolescentes na Internet

mesma linha, o ECA trata da proteção integral conferida a esses indivíduos, considerando, em seu artigo $2^{\circ}$, "criança, a pessoa até 12 (doze) anos de idade incompletos, e adolescente aquela entre 12 (doze) e 18 (dezoito) anos de idade" (BRASIL, 1990).

Não apenas, a Convenção sobre os Direitos da Criança, que dispõe, em seu artigo 1, ser criança todo ser humano com menos de 18 (dezoito) anos de idade, o que, inclusive, denota um rigor maior do que o previsto pelo ECA em relação à proteção destinada à tais sujeitos, também aduz que:

Artigo 3.2. Os Estados Partes se comprometem a assegurar à criança a proteção e o cuidado que sejam necessários para seu bem-estar, levando em consideração os direitos e deveres de seus pais, tutores ou outras pessoas responsáveis por ela perante a lei e, com essa finalidade, tomarão todas as medidas legislativas e administrativas adequadas. (BRASIL, 1990)

Na Europa, o General Data Protection Regulation (GDPR) traz às crianças e aos adolescentes uma proteção específica acerca de seus dados pessoais, partindo do pressuposto de que esses indivíduos podem estar menos conscientes dos riscos, das consequências e das salvaguardas atinentes aos direitos que lhes concernem em relação ao tratamento de dados pessoais. Também, os Estados Unidos, através do Children's Online Privacy Protection Act (COPPA) prevê normas para garantir a privacidade das crianças e dos adolescentes no meio digital.

Nesse contexto, "a adequada e necessária proteção ao menor se realiza mediante o diálogo de todas as fontes. Por isso mesmo, a abordagem do impacto da internet na vida e nos direitos da criança e do adolescente perpassa pelas normas legais já mencionadas [...]" (LIMA; SÁ, 2019, p. 87).

Tendo em vista o arcabouço normativo destinado à proteção das crianças e dos adolescentes, tanto em âmbito nacional, quanto internacional, o legislador brasileiro, ao editar a Lei $\mathrm{n}^{\circ} 13.709$ de 2018, se preocupou em tutelar os dados pessoais das crianças e dos adolescentes inseridos no ambiente virtual, haja vista o fato de que "um terço dos usuários da internet é menor de idade" ${ }^{2}$, segundo relatório publicado pelo Fundo das Nações Unidas para a Infância (UNICEF), no ano de 2018.

\footnotetext{
5 “Um terço dos usuários da internet é menor de idade, revela um relatório publicado nesta semana (6) pelo Fundo das Nações Unidas para a Infância (UNICEF). Agência da ONU fez apelo urgente por ações para proteger meninos e meninas de perigos do mundo virtual, como cyberbullying, exploração sexual e invasão de privacidade." Disponível em: https://nacoesunidas.org/a-cada-segundo-2-criancas-entram-na-internet-pela-1avez-diz-unicef/. Acesso em: 30 jun. 2020.
} 
Para tanto, estabeleceu, no artigo 14, presente na Seção III do seu Capítulo I, a necessidade do respeito ao melhor interesse desses seres em desenvolvimento quando do tratamento de seus dados pessoais: “Art. 14. O tratamento de dados pessoais de crianças e de adolescentes deverá ser realizado em seu melhor interesse, nos termos deste artigo e da legislação pertinente.” (BRASIL, 2018)

Para as crianças, indivíduos com até 12 (doze) anos de idade incompletos, segundo o ECA, o referido tratamento dependerá do consentimento específico e em destaque dado por um de seus pais ou pelo responsável legal, nos termos do $\S 1^{\circ}$ do supracitado artigo.

Não obstante, aduz o $§ 2^{\circ}$ que:

\begin{abstract}
$\S 2^{\circ}$. No tratamento de dados de que trata o $\$ 1^{\circ}$ deste artigo, os controladores deverão manter pública a informação sobre os tipos de dados coletados, a forma de sua utilização e os procedimentos para o exercício dos direitos a que se refere o art. 18 desta Lei. (BRASIL, 2018)
\end{abstract}

Dessa maneira, deve-se “apurar com a máxima precisão se a pessoa que está consentindo com a coleta de dados realmente é um pai ou responsável pelo menor. No mais, deverá saber com clareza qual dado pessoal [...] está sendo coletado" (TEIXEIRA; ARMELIN, 2019, p. 74).

Notório, então, que o consentimento fornecido pelos pais ou pelo responsável legal é a regra no que diz respeito à coleta para o tratamento de dados pessoais de crianças. No entanto, o $\S 3^{\circ}$ do artigo 14 da supramencionada legislação traz, em caráter excepcional, duas hipóteses em que os dados pessoais desses indivíduos podem vir a ser coletados sem esse consentimento, quais sejam, para contatar, justamente, os pais ou o responsável legal, desde que sejam utilizados uma única vez e não sejam armazenados, ou para protege-los, tendo em vista sua condição peculiar de desenvolvimento. Cabe ressaltar que em ambos os casos, de maneira alguma, os dados pessoais coletados poderão ser repassados a terceiro sem o consentimento de que trata o $\S 1^{\circ}$.

De acordo com o disposto no $\S 5^{\circ}$, com as tecnologias disponíveis, o controlador deve realizar todos os esforços razoáveis para verificar que o consentimento específico e em destaque para a realização do tratamento de dados pessoais de crianças foi, de fato, dado por seu responsável. Nesse ponto, há uma clara preocupação do legislador em evitar que os menores de 12 (doze) anos incompletos - as crianças, para o ECA -, tenham acesso a conteúdos impróprios para a sua faixa etária sem a anuência de seus responsáveis, apesar de 
Artigo: A Lei Geral de Proteção de Dados Pessoais e seus Efeitos em Relação à Proteção Especial Destinada às Crianças e aos Adolescentes na Internet

não dispor "de forma específica sobre os meios que deverão ser empregados para garantir a obtenção do consentimento nos termos legais" (YANDRA; SILVA; SANTOS, 2020, p. 238)

Ainda, a Lei $\mathrm{n}^{\mathrm{o}} 13.709$ de 2018 proíbe expressamente, em seu $\S 4^{\circ}$, que os controladores condicionem a participação das crianças em jogos, aplicações de internet ou outras atividades, ao fornecimento de informações pessoais além daquelas estritamente necessárias à sua realização. Dessa feita, tem-se, nesse ponto, a aplicação direta do princípio da necessidade, disposto no artigo $6^{\circ}$, inciso III da supramencionada legislação.

Preconiza a LGPD pela transparência acerca do tratamento de dados pessoais, inclusive no que concerne às crianças e aos adolescentes. Nessa linha, dispõe no $\S 2^{\circ}$ de seu artigo 14 que os controladores deverão manter pública a informação sobre os tipos de dados coletados, a forma de sua utilização e os procedimentos para o exercício do direito da confirmação da existência de tratamento (artigo 18, inciso I); do acesso aos dados (artigo 18, inciso II); da correção de dados incompletos, inexatos ou desatualizados (artigo 18, inciso III); da anonimização, bloqueio ou eliminação de dados desnecessários, excessivos ou tratados em desconformidade com a própria LGPD (artigo 18, inciso III); da portabilidade dos dados a outro fornecedor de serviço ou produto, mediante a requisição expressa [...] (artigo 18, inciso V); da eliminação dos dados pessoais tratados com o consentimento do titular [...] (artigo 18, inciso VI); da informação das entidades públicas e privadas com as quais o controlador realizou uso compartilhado de dados (artigo 18, inciso VII); da informação sobre a possibilidade de não fornecer consentimento e sobre as consequências da negativa (artigo 18, inciso VIII); da revogação do consentimento [...] (artigo 18, inciso IX).

De forma a complementar o sistema de proteção especial destinado ao tratamento de dados pessoais das crianças e dos adolescentes, a Lei n ${ }^{\circ} 13.709$ de 2018 trouxe uma inovação no $\S 6^{\circ}$ de seu artigo 14 , estabelecendo que:

\footnotetext{
$\S 6^{\circ}$. As informações sobre o tratamento de dados referidas neste artigo deverão ser fornecidas de maneira simples, clara e acessível, consideradas as características físico-motoras, perceptivas, sensoriais, intelectuais e mentais do usuário, com uso de recursos audiovisuais quando adequado, de forma a proporcionar a informação necessária aos pais ou ao responsável legal e adequada ao entendimento da criança. (BRASIL, 2018)
}

Nesse sentido, nos moldes da redação do texto legal supramencionado, propicia-se, através de informações claras e acessíveis, a formação de sujeitos conscientes do mundo que 
os cerca e da maneira como as relações interpessoais são construídas no século XXI, tendo em vista o fato de que, na concepção de Maria Dinair Acosta Gonçalves:

\footnotetext{
Superou-se o direito tradicional, que não percebia a criança como indivíduo e o direto moderno do menor incapaz, objeto de manipulação dos adultos. Na era pósmoderna, a criança, o adolescente e o jovem são tratados como sujeitos de direito, em sua integralidade. (GONÇALVES, 2002, p. 15)
}

Dessa maneira, além de salvaguardar o tratamento dos dados pessoais desses indivíduos que se encontram em desenvolvimento, a supramencionada legislação também se preocupou em, gradativamente, inseri-los na sociedade da informação, uma vez que é inerente o seu contato com aparelhos digitais e redes sociais na era tecnológica, indo de encontro ao que ao que dispõe o ECA (artigo $16^{6}$ ) quanto à participação integral do público infantojuvenil na comunidade.

\section{A IMPRESCINDIBILIDADE DO CONSENTIMENTO DOS PAIS OU DO RESPONSÁVEL LEGAL NO TRATAMENTO DE DADOS PESSOAIS DOS ADOLESCENTES}

A LGPD, ao tratar acerca do tratamento de dados pessoais de crianças e adolescentes, estabeleceu, no $\S 1^{\circ}$ de seu artigo 14 , que: “ $\$ 1^{\circ}$. O tratamento de dados pessoais de crianças deverá ser realizado com o consentimento específico e em destaque dado por pelo menos um dos pais ou pelo responsável legal.” (BRASIL, 2018).

É notório, nesse ponto, que silenciou o legislador acerca da necessidade de ao menos um dos pais ou do responsável legal fornecer o consentimento específico e em destaque quando do tratamento de dados pessoais de adolescentes, por se referir no supracitado texto legal apenas às crianças.

Nesse contexto, tendo em vista a delimitação etária trazida pelo ECA, pode ser considerado adolescente o indivíduo entre 12 (doze) e 18 (dezoito) anos. À luz do CC/02, os sujeitos menores de 18 (dezoito) e maiores de 16 (dezesseis) anos são considerados relativamente incapazes para certos atos ou à maneira de os exercer (artigo $4^{\circ}$ ), e os menores

\footnotetext{
${ }^{6}$ Art. 16 do ECA. O direito à liberdade compreende os seguintes aspectos: I - ir, vir e estar nos logradouros públicos e espaços comunitários, ressalvadas as restrições legais; II - opinião e expressão; III - crença e culto religioso; IV - brincar, praticar esportes e divertir-se; V - participar da vida familiar e comunitária, sem discriminação; VI - participar da vida política, na forma de lei; VII -buscar refúgio, auxílio e orientação. (BRASIL, 1990)
} 
Artigo: A Lei Geral de Proteção de Dados Pessoais e seus Efeitos em Relação à Proteção Especial Destinada às Crianças e aos Adolescentes na Internet

de 16 (dezesseis) anos são tidos como absolutamente incapazes de exercer pessoalmente os atos da vida civil $\left(\operatorname{artigo} 5^{\circ}\right.$ ). Dessa feita, conforme seu artigo 1.164:

Art. 1.634. Compete a ambos os pais, qualquer que seja a sua situação conjugal, o pleno exercício do poder familiar, que consiste em, quanto aos filhos:

[...] VII - representá-los judicial e extrajudicialmente até os 16 (dezesseis) anos, nos atos da vida civil, e assisti-los, após essa idade, nos atos em que forem partes, suprindo-lhes o consentimento. (BRASIL, 2002).

Não apenas, aduz a norma civil que são nulos os negócios jurídicos realizados por absolutamente incapazes (artigo 166, inciso I) e anuláveis os praticados por relativamente incapazes (artigo 171, inciso I), haja vista seu artigo 104 elencar como um dos requisitos de validade a capacidade do agente. Para Carlos Roberto Gonçalves, "o negócio é nulo quando ofende preceitos de ordem pública, que interessam à sociedade" (GONÇALVES, 2018, p. 488), e, na mesma linha, refere-se à anulabilidade "à incapacidade do agente" (2018, p. 491).

Assim sendo, é possível depreender que há uma colisão entre as disposições já consolidadas no ordenamento jurídico pátrio quanto à necessidade de o adolescente - aquele maior de 12 (doze) e menor de 18 (dezoito) anos, absoluta ou relativamente incapaz, conforme exposto alhures -, ter o seu consentimento referendado pelo responsável legal na prática dos atos da vida civil, haja vista sua condição de sujeito em desenvolvimento, e o que aduz o supramencionado $\S 1^{\circ}$ da LGPD.

Logo, ao silenciar acerca do consentimento de um dos pais ou do responsável legal para a realização do tratamento de dados pessoais dos adolescentes, sendo suficiente para tanto apenas a anuência do titular, a Lei n ${ }^{\circ} 13.709$ de 2018 abre uma exceção à regra geral das nulidades no âmbito do Direito Civil, bem como fornece uma "carta branca" para o maior de 12 (doze) anos decidir como se dará a disposição dos seus dados pessoais na internet.

Sendo assim, importante considerar que:

\footnotetext{
$\mathrm{Na}$ adolescência o córtex pré-frontal ainda não refreia emoções e impulsos primários. Também nesta fase de formação o cérebro adolescente reduz as sensações de prazer e satisfação que os estímulos da infância proporcionam, o que impulsiona a busca de novos estímulos. Atitudes impensadas, variações de humor, tempestade hormonal, onipotência juvenil são características comuns a esta fase de formação fisiológica do adolescente, justificando tratamento diferenciado por meio da lei especial que o acompanha durante esta etapa da vida. (AMIN et al., 2018, p. 63)
}

Portanto, tendo em vista as considerações tecidas ao longo do presente estudo quanto à premente necessidade de tutelar as crianças e os adolescentes no ambiente digital, o referido 
$\S 1^{\circ}$ deve ser interpretado de forma extensiva, partindo do pressuposto de que "a expressão criança abrange todas as pessoas que encontram sob autoridade parental ou tutela, mesmo com idade superior a 12 anos" (LIMA; SÁ, 2020, p. 28), para que, de fato, seja efetivado no âmbito da LGPD o seu melhor interesse, à luz da proteção integral prevista pelo ordenamento jurídico brasileiro.

\section{CONSIDERAÇÕES FINAIS}

Foi de primordial a edição da Lei no 13.709 de 2018, uma vez que criou um verdadeiro sistema de proteção aos dados pessoais no Brasil. Em consonância com o analisado no presente estudo, sua elaboração propiciou a unificação das normas atinentes à matéria, que se encontravam esparsas pelo ordenamento jurídico brasileiro, tendo sido moldada por dispositivos legais de grande relevância no cenário internacional.

Além de delimitar objetivos, traçar conceitos e definir o âmbito de sua aplicabilidade, a LGPD despendeu uma Seção em seu Capítulo II, composta pelo artigo 14 e parágrafos, na qual preconizou que o tratamento de dados pessoais de crianças e de adolescentes deverá ser realizado com vistas em seu melhor interesse, denotando o entendimento de que esses indivíduos são sujeitos em desenvolvimento, razão pela qual exigem uma proteção especial.

Dessa maneira, é possível depreender que o enunciado no artigo 14 se pautou no arcabouço normativo presente no ordenamento jurídico brasileiro no que diz respeito à proteção integral destinada às crianças e aos adolescentes, como também em disposições internacionais relativas ao tema.

Contudo, é notável que houve, nesse ponto, uma falta de cautela aos detalhes, em especial no que diz respeito ao silêncio quanto à necessidade de ao menos um dos pais ou do responsável legal fornecer consentimento específico e em destaque para a realização do tratamento de dados pessoais dos adolescentes, tendo em vista a redação do $\S 1^{\circ}$ de seu artigo 14, o que vai no sentido contrário à regra das nulidades presente na norma civil e às disposições atinentes no próprio sistema de proteção de dados pessoais inserido no Brasil pela LGPD acerca do melhor interesse desses indivíduos.

Sendo assim, é primordial a realização de uma interpretação extensiva para o dispositivo legal em apreço, a fim de concretizar, na égide do sistema construído pela LGPD no Brasil, a proteção especial não apenas em relação às crianças, como também aos adolescentes, nos moldes do que aduz a legislação e a doutrina brasileira acerca do tema. 
Artigo: A Lei Geral de Proteção de Dados Pessoais e seus Efeitos em Relação à Proteção Especial Destinada às Crianças e aos Adolescentes na Internet

Desse modo, conclui-se que a entrada em vigor da Lei $n^{\circ} 13.709$ de 2018 representou para o Brasil um avanço significativo no que diz respeito à tendência mundial de regular a proteção de dados pessoais, tendo em vista a forma como as relações interpessoais têm sido construídas na contemporaneidade, inclusive no que concerne às crianças e aos adolescentes.

\section{REFERÊNCIAS}

AMIM, A. R.; SANTOS, A. M. S. dos; MORAES, B. M. de; CONDACK, C. C.; BORDALlO, G. A. C.; RAMOS, H. V.; MACIEL, K. R. F. L. A.; RAMOS, P. P. de O. C.; TAVARES, P. S. Curso de Direito da Criança e do Adolescente: Aspectos Teóricos e Práticos. $11^{a}$ Ed. São Paulo. Editora Saraiva, 2018.

BRASIL. Constituição da República Federativa do Brasil de 1988. Diário oficial [da] União, 5 out. 1988. Brasília, DF: 1988a. Disponível em:

http://www.planalto.gov.br/ccivil_03/constituicao/constituicaocompilado.htm. Acesso em: 26 abr. 2020.

BRASIL. Decreto no 99.710, de 21 de novembro de 1990. Diário oficial [da] União, 22 nov. 1990. Brasília, DF: 1990a. Disponível em:

http://www.planalto.gov.br/ccivil_03/decreto/1990-1994/d99710.htm. Acesso em: 30 jun. 2020.

BRASIL. Lei no 8.069, de 13 de julho de 1990. Diário oficial [da] União, 16 jul. 1990. Brasília, DF: 1990a. Disponível em: http://www.planalto.gov.br/ccivil_03/leis/18069.htm. Acesso em: 26 abr. 2020.

BRASIL. Lei n⿳0 10.406, de 10 de janeiro de 2002. Diário oficial [da] União, 11 jan. 2002. Brasília, DF: 2002a. Disponível em: http://www.planalto.gov.br/ccivil_03/leis/2002/110406.htm. Acesso em: 26 abr. 2020. BRASIL. Lei no 12.527, de 18 de novembro de 2011. Diário oficial [da] União, 18 nov. 2011. Brasília, DF: 2011a. Disponível em: http://www.planalto.gov.br/ccivil_03/_ato20112014/2011/lei/112527.htm. Acesso em 03 mai. 2020.

BRASIL. Lei no 12.965, de 23 de abril de 2014. Diário oficial [da] União, 24 abr. 2014. Brasília, DF: 2014a. Disponível em: http://www.planalto.gov.br/ccivil_03/_ato20112014/2014/lei/112965.htm. Acesso em: 03 mai. 2020.

BRASIL. Lei no 13.709, de 14 de agosto de 2018. Diário oficial [da] União, 15 ago. 2018. Brasília, DF: 2018a. Disponível em: : http://www.planalto.gov.br/ccivil_03/_ato20152018/2018/lei/L13709.htm. Acesso em: 23 fev. 2020.

CASTELLS, M. A Era da Informação: Economia Sociedade e Cultura. Volume 1. A Sociedade em Rede. Trad. Roneide Venancio Majer. $6^{a}$ Ed. São Paulo. Editora Paz e Terra, 2002. 
Dados pessoais, 'petróleo do século XXI', exigem mais cuidados. Jornal da PUC. 02 de junho de 2017. Disponível em: http://jornaldapuc.vrc.puc-

rio.br/cgi/cgilua.exe/sys/start.htm?infoid=5247\&sid=53. Acesso em: 26 abr. 2020.

GONÇALVES, Carlos Roberto. Direito Civil Brasileiro: Parte Geral. 16 ${ }^{\text {a }}$ Ed. São Paulo. Editora Saraiva. 2017.

GONÇALVES, Carlos Roberto. Direito Civil Brasileiro: Contratos e Atos Unilaterais. 15 Ed. São Paulo. Editora Saraiva. 2018.

GONÇALVES, Maria Dinair Acosta. Proteção Integral: Paradigma Multidisciplinar do Direito Pós-Moderno. Porto Alegre. Editora Alcance, 2002.

LIMA, Taísa Maria Macena de; SÁ, Maria de Fátima Freire de. Ensaio sobre a Infância e a Adolescência. $2^{\circ}$ Ed. Belo Horizonte. Editora Arrais Editora Ltda. 2019.

LIMA, Taísa Maria Macena de; SÁ, Maria de Fátima Freire de. As pessoas com Deficiência no Microssistema de Proteção de Dados Pessoais. Revista Duc In Altum Cadernos de Direito, vol. 12, n 26, jan-abr, 2020, p. 27-55.

O avanço tecnológico e a sociedade contemporânea. Jornal da PUC Campinas. 19 de setembro de 2017. Disponível em: http://jornal.puc-campinas.edu.br/o-avanco-tecnologico-ea-sociedade-contemporanea/. Acesso em: 26 abr. 2020.

PEREIRA, Tânia da Silva. O Princípio do Melhor Interesse da Criança: da Teoria à Prática. Revista Brasileira de Direito de Família. Porto Alegre, n. 6, 2000, p. 31-49.

TEIXEIRA, Tarcísio; ARMELIN, Ruth Maria Guerreiro da Fonseca. Lei Geral de Proteção de Dados Pessoais Comentada Artigo por Artigo. $1^{\circ}$ Ed. Salvador. Editora Juspodivm. 2019.

YANDRA, B. F. F.; SILVA, A. C. A.; SANTOS, J. G.. Lei Geral de Proteção de Dados e a Tutela dos Dados Pessoais de Crianças e Adolescentes: a Efetividade do Consentimento dos Pais ou Responsáveis Legais. Revista Internet\&Sociedade. São Paulo, n. 1, v. 1, fev., 2020, p. 230-249. 